Article

\title{
Evaluation of Satellite Rainfall Estimates in the Pra Basin of Ghana
}

\author{
Collins Owusu *, Kwaku Amaning Adjei and Samuel Nii Odai \\ Department of Civil Engineering, Kwame Nkrumah University of Science \& Technology, Private Mail Bag, \\ Kumasi, Ghana; nanakadjei@gmail.com (K.A.A.); snodai@yahoo.com (S.N.O.) \\ * Correspondence: coleknust@yahoo.co.uk; Tel.: +233-277-036-223
}

\begin{abstract}
Satellite-based rainfall estimation products provide a vital alternative source of rainfall data in areas where conventional precipitation measurement is not readily available. In order to facilitate the use of these products there is the need to evaluate their accuracies. This study evaluated the accuracy of three satellite rainfall products; TMPA 3B42RT, TMPA 3B42 and CMORPH in the Pra basin $\left(23,330 \mathrm{~km}^{2}\right)$ of Ghana. The evaluation was through the point-to-pixel method by comparing $0.25^{\circ} \times 0.25^{\circ}$ satellite grids to gauged rainfall based on gauge locations and analyzed statistically using correlation coefficient (r), bias and percent bias (pBias) as the performance verification methods. Seven (7) gauge stations with no missing data for the period of 2003-2008 was used in the evaluation. The analysis was based on daily, monthly, annual and seasonal timescales. Our results showed a good correlation between the TMPA products and the gauged data on all timescales considered. The CMORPH on the other hand showed huge overestimation at all gauge locations. The TMPA 3B42 was seen to be the best amongst the three products. The overall rainfall in the basin was well depicted by the TMPA 3B42 and 3B42RT. Although there wasn't a perfect match between the 3B42RT and 3B42 products and the gauged rainfall, these products can be used to supplement gauged rainfall measurements in the basin and in estimation of rainfall in ungauged basins with similar characteristics.
\end{abstract}

Keywords: rainfall; TMPA; CMORPH; Pra basin; satellite-based precipitation; Ghana

\section{Introduction}

Rainfall is a vital component of the hydrological cycle. It is an important atmospheric input into land surface hydrologic models. Rainfall gauges provide direct physical measurement of rainfall and accuracy in its measurement is very crucial in the reliability of simulated hydrologic processes. To achieve a satisfactory prediction from rainfall-runoff models, rainfall gauges should be well distributed spatially in the study area. Proper monitoring of rainfall requires a dense rain gauge network which is often not the case in developing countries like Ghana because of low budget allocation to agencies responsible for collecting the meteorological data [1]. Areas with relatively dense gauge network sometimes have large proportion of missing values, unreliability of the records and limited accessibility to available data [2].

Weather radars can offer a spatial measure of rainfall; however, these are prone to inaccuracies due to complex atmospheric conditions, height of the radar beam, beam blocking and variations in the reflectivity-rainfall rate relationships [3]. Moreover, weather radars are either sparse or nonexistent in developing countries. According to [4], provision of weather radars in Africa is not a feasible proposition on the grounds of cost, technical infrastructure and topography.

Satellite-based rainfall estimation (SRFE) products provides a potential alternative source of deriving data for hydrological models in regions where conventional rainfall measurement is not readily available or adequate due to their high spatial and temporal resolution. Satellite-based rainfall measurement instruments collect data mainly at thermal infrared (TIR) and passive microwave (PMW) wavelengths which can be used to estimate rainfall rates. The satellite systems have been divided into two; geosynchronous earth orbit (GEO) satellites and low earth orbiting (LEO) satellites 
[5]. The GEO satellites makes use of thermal infrared (TIR) sensors which provides excellent depiction of the movement of clouds and weather systems, but their relationship to rain rate is indirect [6]. The GEO satellites have a revisit times of 15-30 min which is very frequent [7]. The LEO satellites have passive and active microwave (MW) sensors which have more direct and physical inference of rainfall but suffers from poor temporal sampling. Many satellite rainfall algorithms have been developed to estimate rainfall by using either IR or MW or a combination of information from the more accurate MW with the more frequent but less accurate IR to take advantage of their strengths.

The Tropical Rainfall Measuring Mission (TRMM) Multisatellite Rainfall Analysis (TMPA) method [8] uses both PMW and TIR. This method creates estimates that contain MW-derived rainfall estimates when and where MW data are available and uses MW data to calibrate the IR-derived estimates when MW data is not available. The TMPA produces two versions of rainfall products; near-real-time version (3B42RT) and the post-real-time research version (3B42). The 3B42 uses monthly rain gauge data for bias adjustment. The CPC Morphing technique (CMORPH) method [9] uses rainfall estimates that have been derived from low orbiter satellite microwave observations exclusively. TIR imagery is not used to estimate rainfall but rather to interpolate between two PMWderived rainfall intensity fields.

Satellite-based rainfall products have their own shortcomings since they are not direct estimates of rainfall. There are variety of error sources such as gaps in revisit times, poor direct relationship between remotely sensed signals and rainfall rate, atmospheric effects that modify the radiation field [7]. It is therefore crucial to evaluate the accuracies of these products and this can be done by direct comparison of the satellite rainfall estimates to the rain gauge data or based on their predictive ability of streamflow rate in a hydrological model. The first method is what is considered in this study. Little work has been done to evaluate the suitability of satellite-based rainfall data in Ghana. [1] studied how TRMM satellite-derived rainfall compares with ground-measured values and the possibility of using it to complement ground-measured rainfall in the Black Volta basin of Ghana.

The Pra basin in Ghana provides a good example of a case where satellite-based rainfall could be very vital. This study, therefore, evaluates how well the TMPA 3B42, TMPA 3B42RT and CMORPH rainfall estimates compares with rain gauged ones in the Pra basin of Ghana.

\section{Materials and Methods}

\subsection{Description of Study Area}

The Pra Basin is located between Latitudes $5^{\circ} \mathrm{N}$ and $7^{\circ} 30^{\prime} \mathrm{N}$, and Longitudes $2^{\circ} 30^{\prime} \mathrm{W}$, and $0^{\circ}$ $30^{\prime} \mathrm{W}$, in south-central Ghana. The total area of the basin is approximately $23,330 \mathrm{~km}^{2}$ (Figure 1 ). The topography is characterized by relatively flat land in the southern half with few peaks in the mid to northern sections of the basin. The highest elevations in the basin are located in the northern sections and the borders of the eastern parts where elevations of up to $800 \mathrm{~m}$ above sea level are common. Vegetation of the basin is of moist semi-deciduous forest type. Currently, the main land cover types are estimated as follows: Agricultural $(60 \%)$, forest $(30 \%)$, grassland and human settlement cover $10 \%$. Some isolated forest reserves and large established commercial tree plantations contribute to the share of the remaining forest [10]. The basin has two wet seasons: the major season from March to July, and a minor season from September to November [11] as cited by [12]. The basin comes strongly under the influence of the moist south-west monsoons during the rainy season which is due to the movement of the Inter Tropical Convergence Zone (ITCZ). The mean annual rainfall is relatively high, about $1,500 \mathrm{~mm}$ but is also very variable, ranging between $1300 \mathrm{~mm}$ and $1900 \mathrm{~mm}$. The basin is warm and moist throughout most of the year. Relative humidity is between $70 \%-80 \%$ throughout the year. The average maximum and minimum temperatures are $31^{\circ} \mathrm{C}$ and $21^{\circ} \mathrm{C}$, respectively, for the cooler periods of June-September/October [13]. 


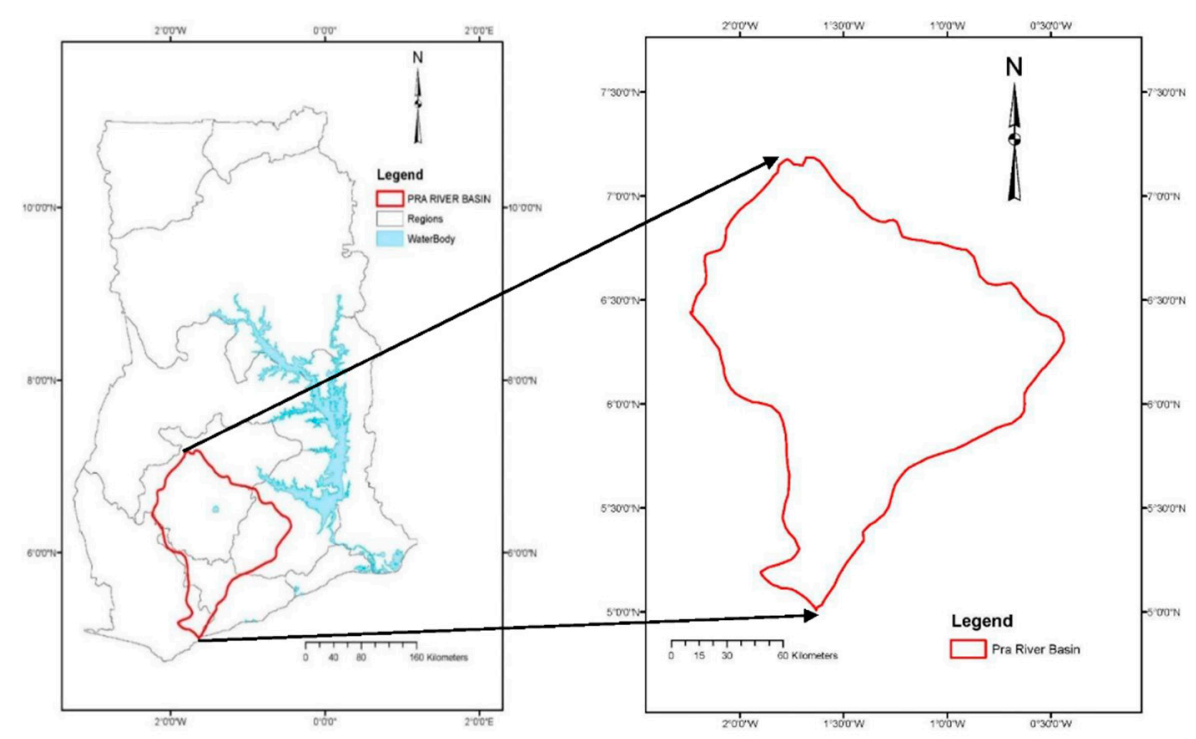

Figure 1. Location map of the study area

\subsection{Data Sources and Processing}

\subsubsection{Gauged Rainfall Data}

A gauge-based daily rainfall dataset for the study period of 2003-2008 obtained from the Ghana Meteorological Agency was used as a reference dataset to evaluate the satellite-derived rainfall estimates. The choice of the study period was based on a common time between gauges and the SRFEs where the selected gauges had no missing data. Using a Thiessen polygon analysis of the rain gauge network in and around the Pra basin, 22 gauge stations were found to have an influence on the basin. Of the 22 stations identified some had several years of missing data and others had very short durations. Seven (7) of out of the 22 stations (Table 1) were found to have no missing data for the period under study and was therefore used for the analysis. Locations and distributions of the 7 stations can be seen in Figure 2.

Table 1. List of rain gauges used in the study.

\begin{tabular}{cccccc}
\hline Station & Location & Latitude & Longitude & Elevation $(\mathbf{m})$ & Type \\
\hline 1 & Abetifi & 6.67 & -0.75 & 594.7 & Synoptic \\
2 & Agogo & 6.78 & -1.08 & 457.5 & Other \\
3 & Akrokeri & 6.30 & -1.65 & 261.4 & Other \\
4 & Dunkwa & 5.97 & -1.78 & 158.6 & Other \\
5 & Fumso & 6.12 & -1.48 & 147.1 & Other \\
6 & Kumasi Airport & 6.72 & -1.60 & 286.3 & Synoptic \\
7 & Akim Oda & 5.93 & -0.98 & 139.4 & Synoptic \\
\hline
\end{tabular}




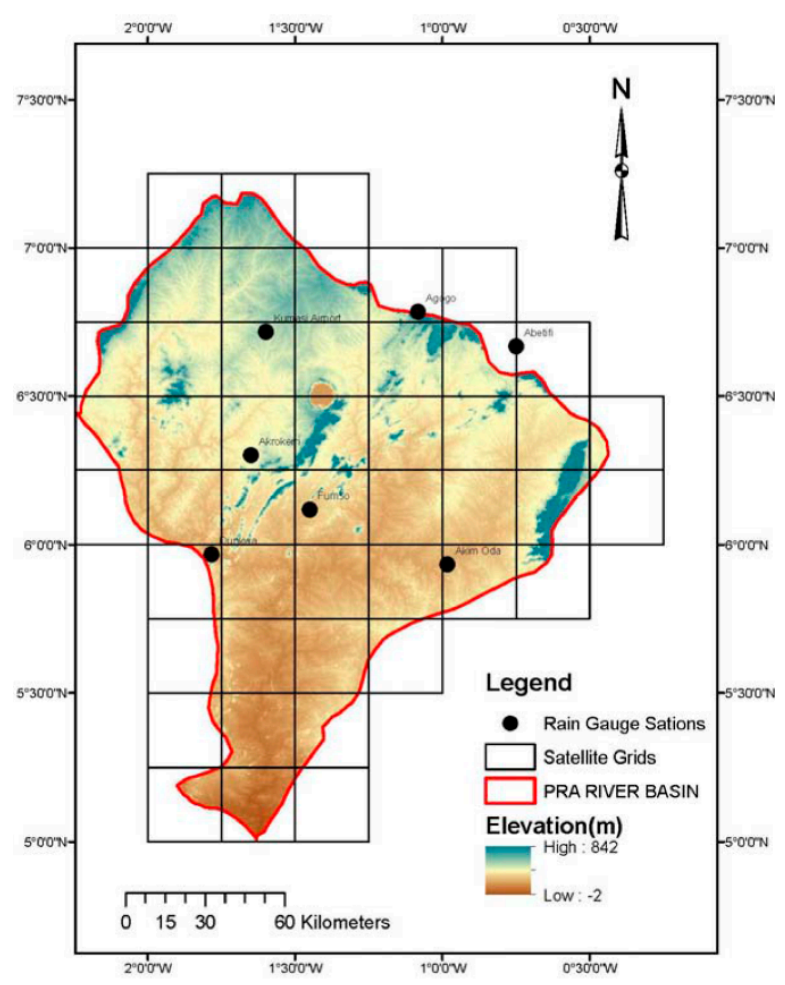

Figure 2. Spatial distribution of gauge stations and satellite grids

\subsubsection{Satellite Rainfall Data}

This section provides a brief description of the satellite rainfall products considered under this study (Table 2) and the source of the data.

Table 2. List of satellite rainfall products used in the study.

\begin{tabular}{cccccc}
\hline & & \multicolumn{2}{c}{ Resolution } & & \\
\cline { 3 - 4 } No. & Name & Spatial & Temporal & Availability & Corrected by gauges \\
\hline 1 & TMPA 3B42 & $0.25^{\circ}$ & $3 \mathrm{~h}$ & $10-15$ days & Yes \\
2 & TMPA 3B42-RT & $0.25^{\circ}$ & $3 \mathrm{~h}$ & $9 \mathrm{~h}$ & No \\
3 & CMORPH & $0.25^{\circ}$ & $3 \mathrm{~h}$ & $18 \mathrm{~h}$ & No \\
\hline
\end{tabular}

The TMPA 3B42 and 3B42RT (version 7) have 3-hour temporal resolution and a $0.25^{\circ} \times 0.25^{\circ}$ spatial resolution (Figure 2) in a global belt extending from latitude $50^{\circ} \mathrm{S}$ to $50^{\circ} \mathrm{N}$. These products are produced by a joint space mission between National Aeronautics and Space Administration (NASA) and the Japan Aerospace Exploration Agency (JAXA) designed to monitor and study tropical rainfall. The 3B42RT is the near-real-time experimental version and the 3B42 is the post-real-time research version which is adjusted by monthly rain gauge data. 3B42RT is released in about $9 \mathrm{~h}$ after real time and 3B42 in about 10-15 days after the end of each month. The TMPA estimates are produced in four stages; (1) the microwave rainfall estimates are calibrated and combined, (2) infrared rainfall estimates are created using the calibrated microwave rainfall, (3) the microwave and IR estimates are combined, and (4) rain gauge data are incorporated for rescaling to monthly data [8]. The primary input data source is passive microwave data which is collected by a variety LEO satellites, including the Microwave Imager (TMI) on TRMM, Special Sensor Microwave Imager (SSM/I) on Defense Meteorological Satellite Program (DMSP) satellites, Advanced Microwave Scanning RadiometerEarth Observing System (AMSR-E) on Aqua, and the Advanced Microwave Sounding Unit-B (AMSU-B) on the National Oceanic and Atmospheric Administration (NOAA) satellite series. The second major data source for the TMPA is the infrared (IR) data that are being collected by the international constellation of GEO satellites [8]. The TMPA data used in this study was acquired using 
the GES-DISC Interactive Online Visualization and Analysis Infrastructure (Giovanni) as part of the NASA's Goddard Earth Sciences (GES) Data and Information Services Center (DISC).

The Climate Prediction Center morphing method (CMORPH) product uses IR-based cloud tracking to interpolate between successive rainfall fields derived from passive microwave observations. Motion vectors derived from half-hourly interval geostationary satellite IR imagery to propagate the relatively high quality rainfall estimates derived from passive microwave data. A timeweighted linear interpolation is used to morph the shape and intensity of the rainfall features [9]. The PMW-derived rainfall estimates that are presently used in CMORPH are generated from data obtained from SSM/I, AMSU-B and TMI [9]. The rainfall estimates are available on $0.07277^{\circ} \times 0.07277^{\circ}$ spatial resolution over the global $60^{\circ} \mathrm{S}$ to $60^{\circ} \mathrm{N}$ in $30 \mathrm{~min}$ temporal resolution. The $0.25^{\circ} \times 0.25^{\circ}$ and 3hour resolution version was used in this study. The CMORPH dataset was obtained from the Climate Prediction Center, National Weather Service, NOAA, U.S. Department of Commerce

\subsubsection{Data Processing}

The TMPA data was exported in ASCII format from the source which was then processed with Notepad++ (version 6.6.9). The accumulated rainfall for the 3-hour $0.25^{\circ} \times 0.25^{\circ}$ grids were imported to Microsoft Excel after processing. Daily accumulated rainfall was then computed for each grid for a particular day by summing the 3-hour rainfall from 9am on that day to 9am the next day, this is in accordance with the time span used by GMET in measuring daily rainfall in Ghana. The $0.25^{\circ} \times 0.25^{\circ}$ grid map was plotted in together with the rainfall gauge locations. Comparison with gauge stations was done by using the point-to-pixel analysis. Rainfall data observed from selected stations were compared with respective satellite rainfall estimate for the grid within which the station is located. This method was used in a study conducted by [14] in which they validated TMPA, PERSIANN, CMORPH, RFE, GPROF, GSMap-MVK satellite products over four basins in Africa.

The CMORPH 3-hour $0.25^{\circ} \times 0.25^{\circ}$ grids were downloaded in netCDF file format. The files for each year were combined into one file by using NCO software (netCDF Operators). The final netCDF files were imported into Microsoft Excel using NetCDF4Excel, an add-in for excel. Daily accumulated rainfall for each grid and comparison was done in the same way as the TMPA data. Summary of the methodology used can be seen in Figure 3.

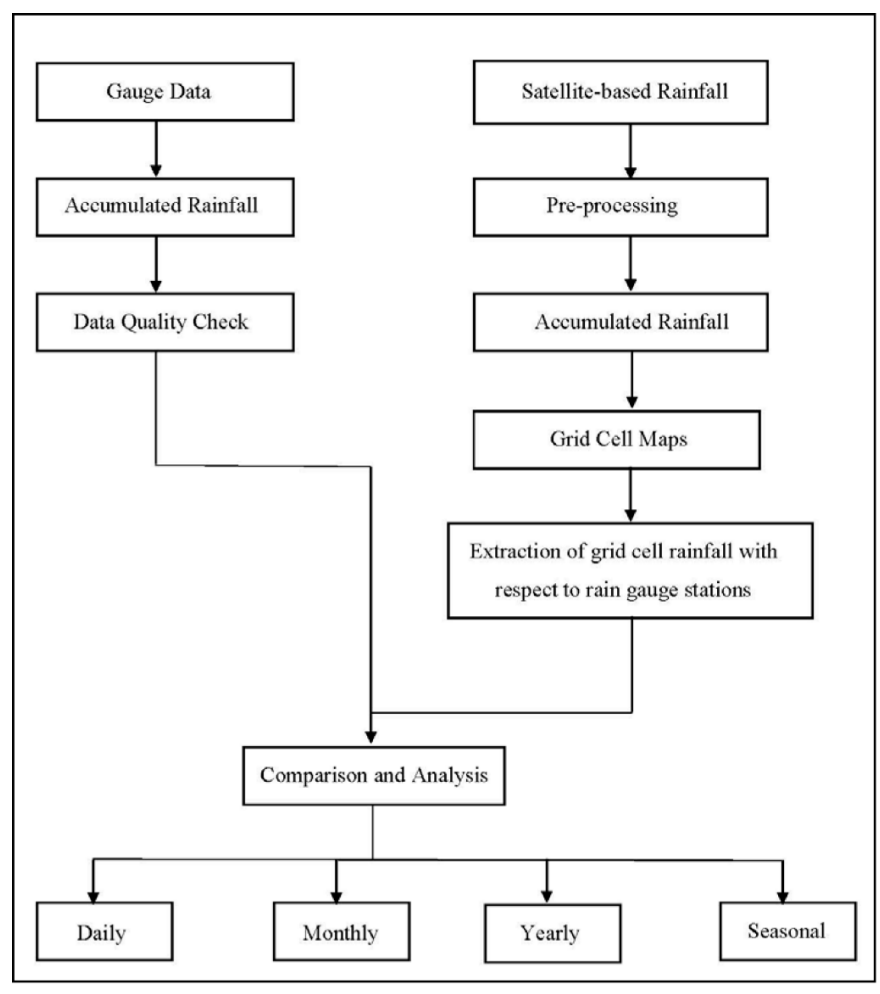

Figure 3. Flowchart of methodology of rainfall analysis 


\subsection{Performance Statistical Methods}

To assess how well the satellite rainfall products perform against the rain gauge measured values quantitatively, the following set of performance statistical methods were used: correlation coefficient (r), bias and percent bias (pBias) (Equations 1-3). Statistics were calculated for daily, monthly, yearly and seasonal time series.

$$
\begin{gathered}
\text { Correlation coefficient }=\frac{\sum_{i=1}^{n}\left(G_{i}-\bar{G}\right)\left(S_{i}-\bar{S}\right)}{\sqrt{\sum_{i=1}^{n}\left(G_{i}-\bar{G}\right)^{2}} \times \sqrt{\sum_{i=1}^{n}\left(S_{i}-\bar{S}\right)^{2}}} \\
\text { Bias }(\mathrm{mm})=S_{i}-G_{i} \\
p B I A S=\frac{\sum_{i=1}^{n}\left(S_{i}-G_{i}\right)}{\sum_{i=0}^{n} G_{i}} \times 100
\end{gathered}
$$

Where $S$ is the satellite estimated value, $G$ is the rain gauge value and $n$ is the number of samples. The correlation coefficient measures the strength of the linear relationship between the gauge observations and the satellite measurements. The percent bias measures the average tendency of the satellite estimates to be larger or smaller than the average gauge values [15], positive or negative values indicate overestimation or underestimation bias respectively.

\section{Results and Discussions}

\subsection{Daily Rainfall Analysis}

Coefficient of correlation, $R$ and percent bias (\% Bias) was computed for the TMPA 3B42, TMPA 3B42-RT and CMORPH products. All the satellite products considered showed a moderate positive linear relationship ranging from 0.31 to 0.58 on a daily time scale (Figure 4).

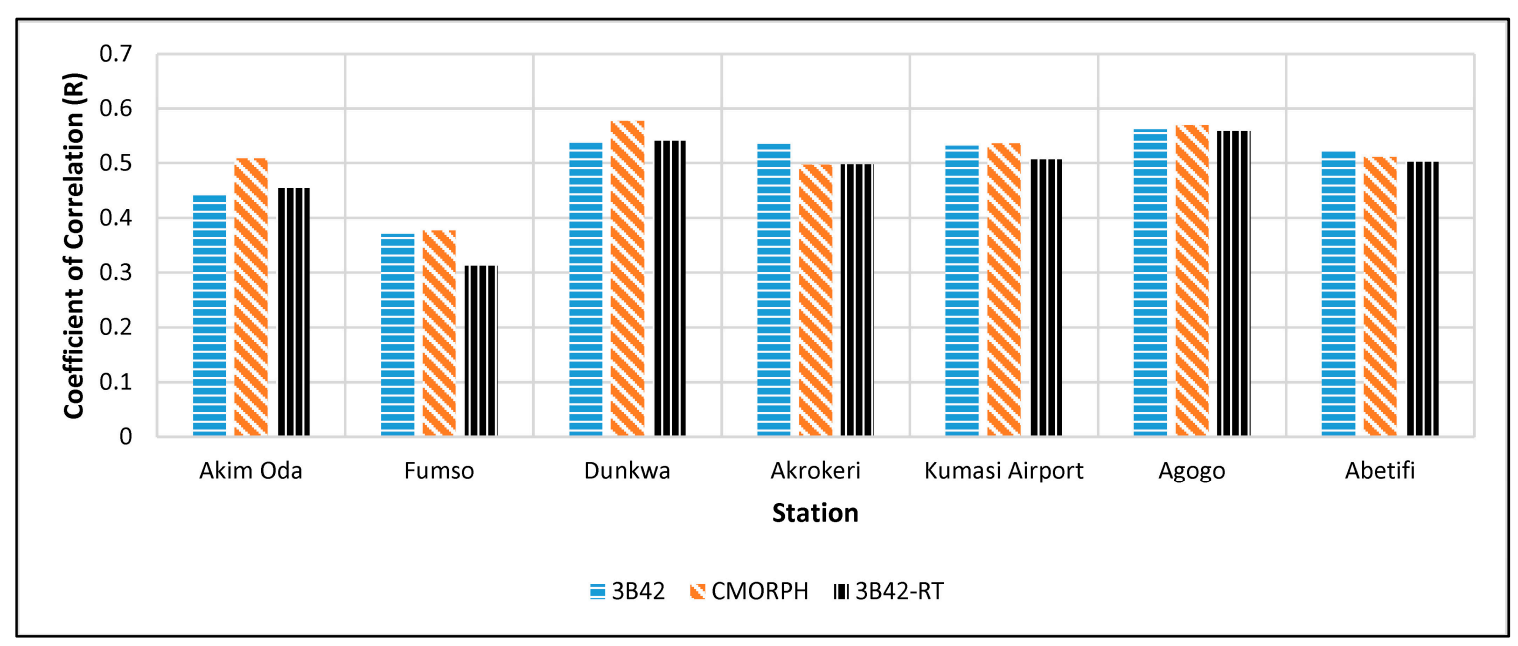

Figure 4. Correlation coefficient $(R)$ between the daily rainfall records obtained from the SRFEs and the rain gauges for the study period at the various stations.

Figure 5 shows that, CMORPH relatively has a high tendency of overestimating the rainfall (32$44 \%$ ). TMPA 3B42 and TMPA 3B42-RT shows maximum of $14.2 \%$ and $17 \%$ tendency of overestimation respectively which manifested in 6 out of the 7 stations considered. Although the satellite products performed poorly on a daily timescale, a scatter plot of the averaged accumulated daily rainfall from all 7 stations versus the average from the satellite grids as shown in Figure 6 shows a good correlation ranging between 0.72 and 0.76 . This shows that the overall daily rainfall in the basin is well represented by all the satellite products. 


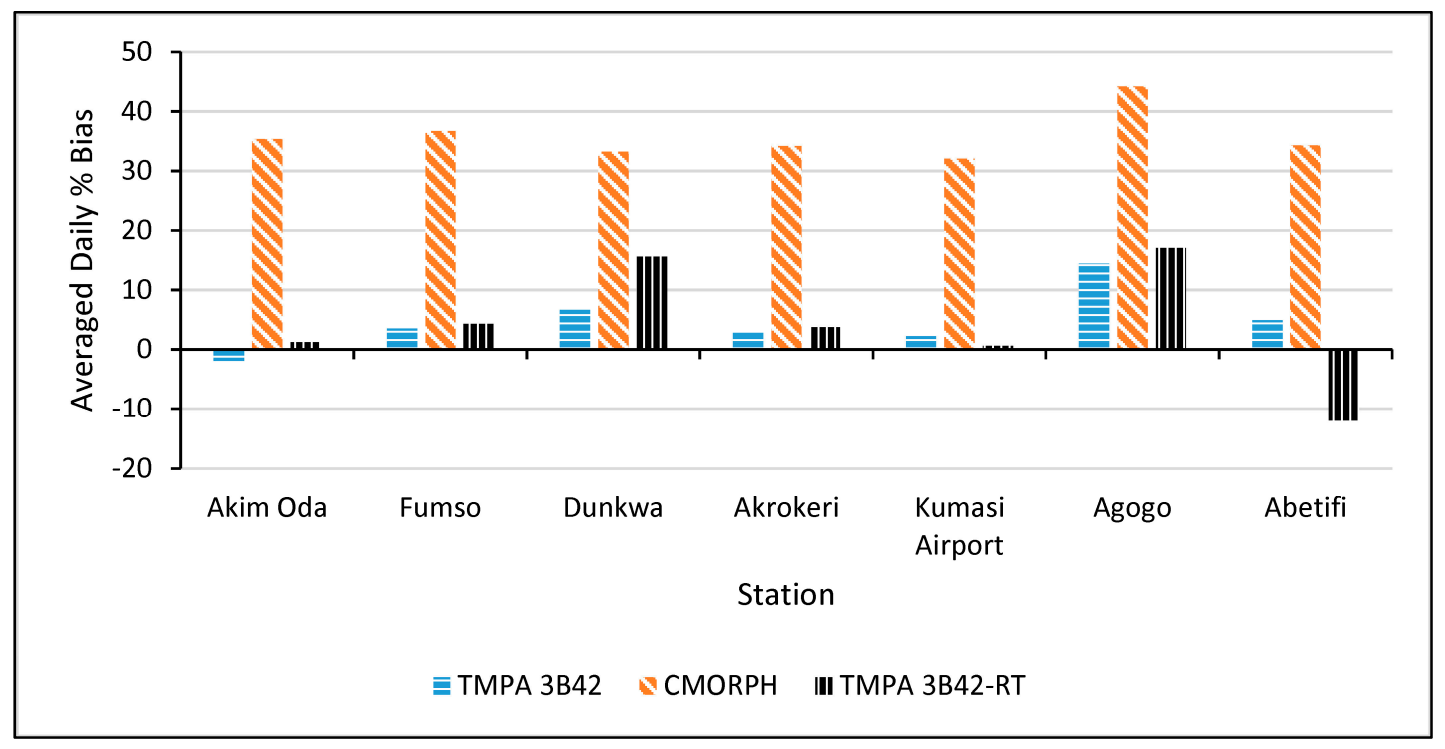

Figure 5. Average percent bias (\% Bias) of daily rainfall obtained from the SRFEs and the rain gauges for the study period.

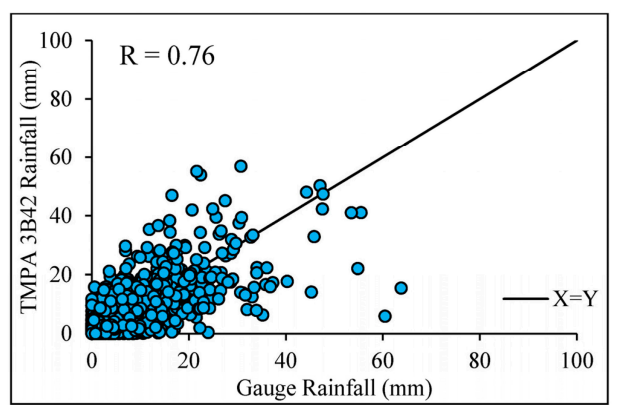

(a)

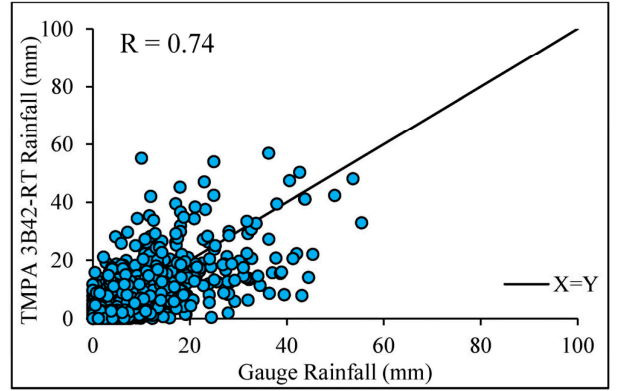

(b)

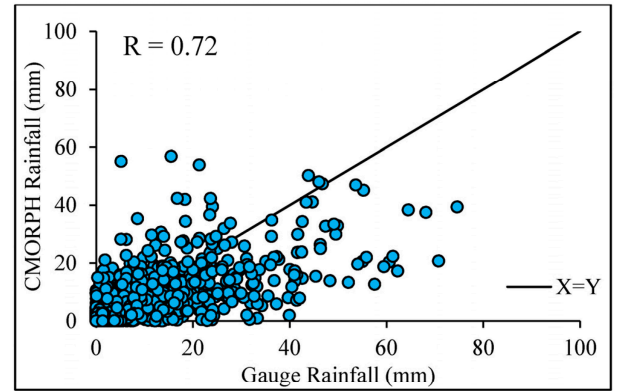

(c)

Figure 6. Plot of averaged daily rainfall $(\mathrm{mm})$ from all 7 stations obtained from SRFEs versus rain gauges: (a) TMPA 3B42; (b) TMPA 3B42-RT and (c) CMORPH, 2003-2008 [Coefficient of Correlation (R)].

\subsection{Monthly Rainfall Analysis}

Coefficient of Correlation (R) was computed for all the 7 selected rain gauge stations. An analysis was carried out to assess if there is any relationship between the elevation of the stations and the computed $\mathrm{R}$ for each of the satellite products. This was carried out to assess how the satellite products perform at different locations with respect to elevations. A study conducted by [16] in some basins in Ethiopia revealed that bias in satellite rainfall estimates depended on elevation. Figure 7 shows that there is no clear relation between the correlation coefficient obtained at the stations and the elevations of the stations. 


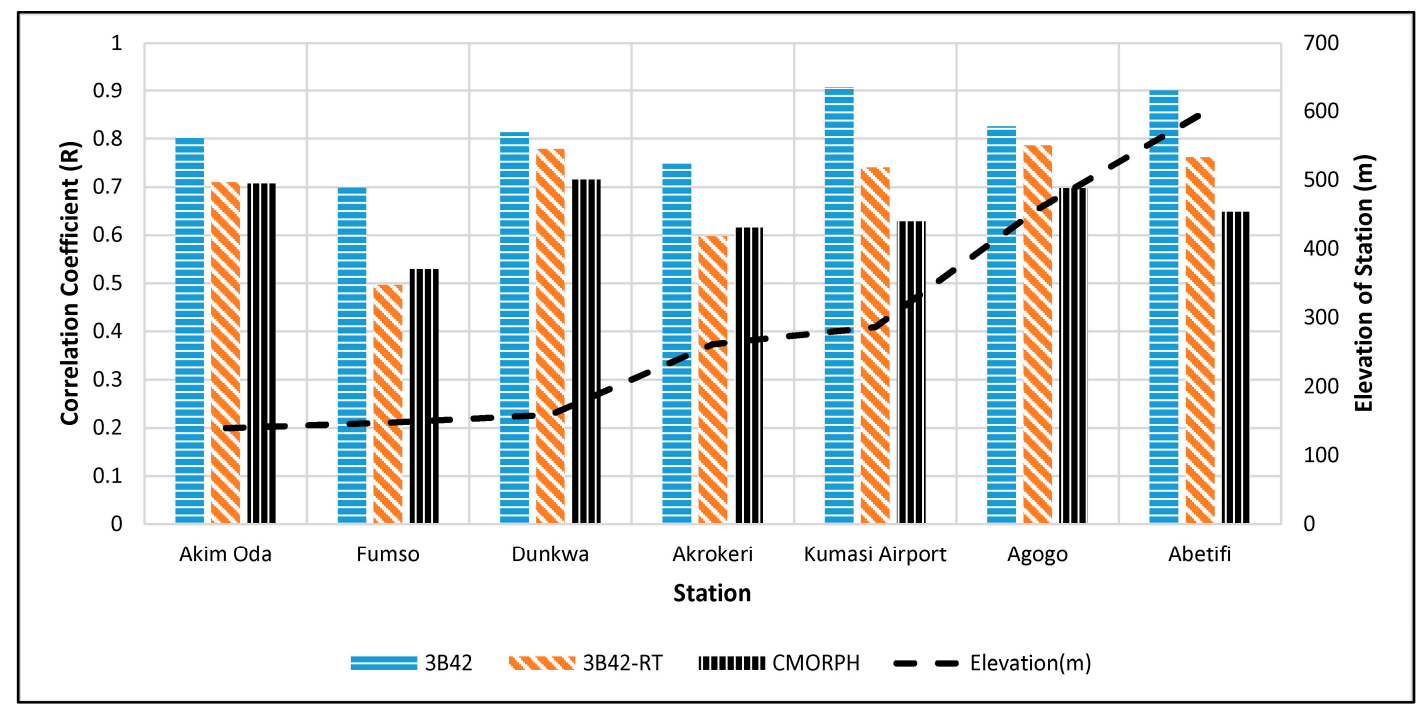

Figure 7. Correlation coefficient $(\mathrm{R})$ between the accumulated monthly rainfall records obtained from the SRFEs and the rain gauges for the study period at the various stations and a plot of the elevations of the various stations.

The computed $\mathrm{R}$ all for all the stations and all satellite products ranged from 0.50 to 0.91 this show a moderate to strong positive linear relationship between the SRFEs and rain gauge values at a monthly time scale. The TMPA 3B42 has a very strong linear relationship with the gauged rainfall with $\mathrm{R}$ ranging from 0.70-0.91. TMPA 3B42-RT (0.50-0.79) and CMORPH (0.53-0.72) showed a moderate to strong linear relationship, although the CMORPH tends to mostly overestimate the rainfall at all 7 stations. Scatter plots showing the correlation between averaged accumulated monthly rainfall for the satellite and gauge data from all 7 stations which represents the overall rainfall estimation for the basin as shown in Figure 8 shows a very good performance for all satellite products. However, the high tendency of overestimation of rainfall by the CMORPH also manifested here in which it overestimated the rainfall in 42 months out of the total 72.

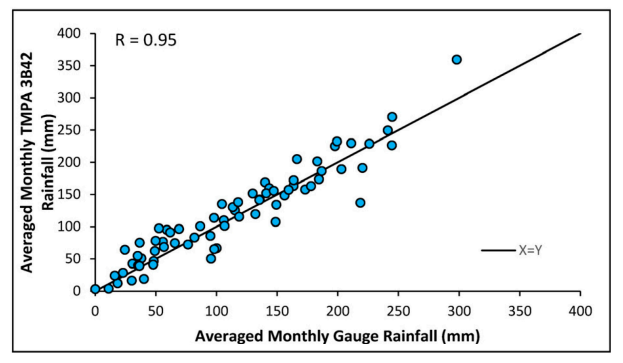

(a)

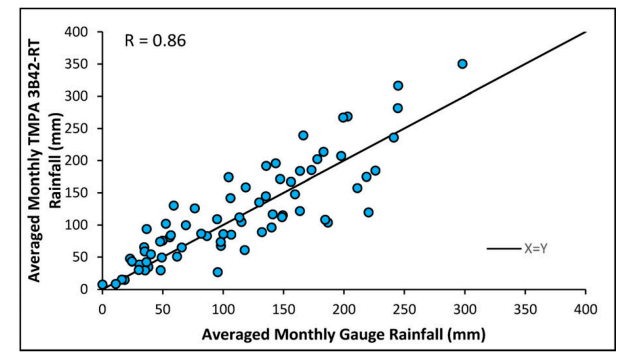

(b)

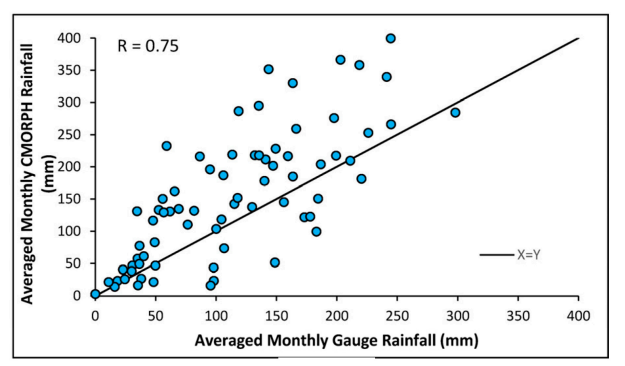

(c)

Figure 8. Plot of average monthly rainfall $(\mathrm{mm})$ from all 7 stations obtained from SRFEs versus rain gauges: (a) TMPA 3B42; (b) TMPA 3B42-RT and (c) CMORPH, 2003-2008 [Coefficient of Correlation (R)]. 
A plot of the average monthly error bias for all the 7 stations was carried out to see the extent of overestimation or underestimation of the rainfall by the SRFEs (Figure 9). Figure 9 shows that, the total number of months for which rainfall was overestimated by the satellite products far exceeds that of the underestimation. On the average, the TMPA 3B42 and 3B42-RT shows an overestimation of $5.09 \mathrm{~mm}$ and $4.94 \mathrm{~mm}$ respectively whiles the CMORPH grossly overestimates the rainfall at a bias of $40.25 \mathrm{~mm}$. This shows that, on the average all the satellites products considered in this study overestimates rainfall in the basin on a monthly time scale.

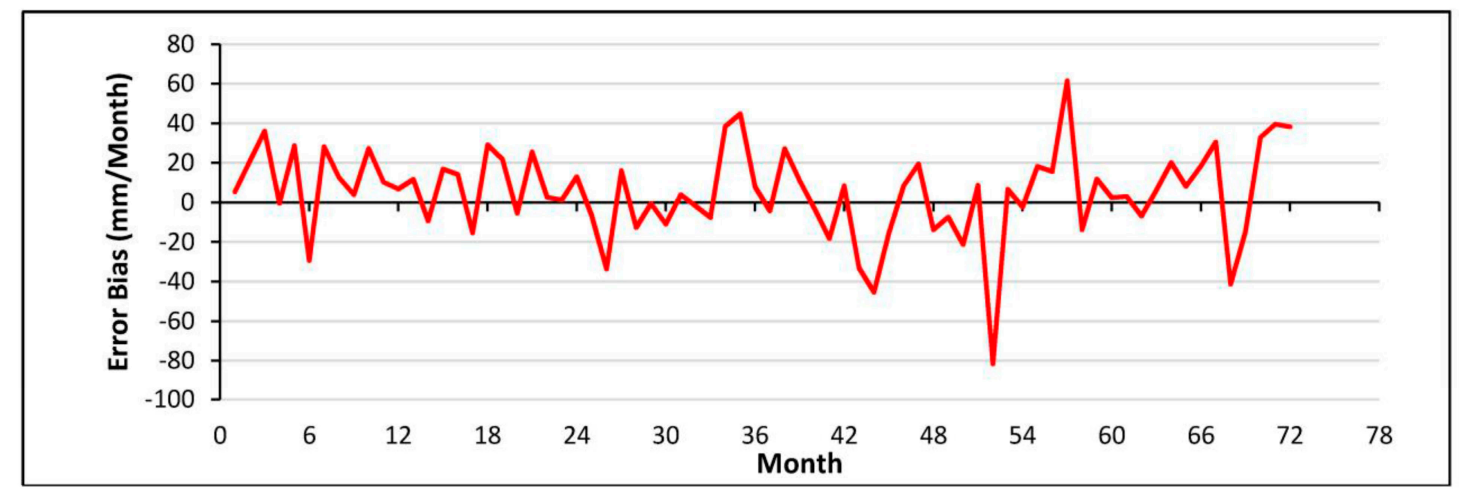

(a)

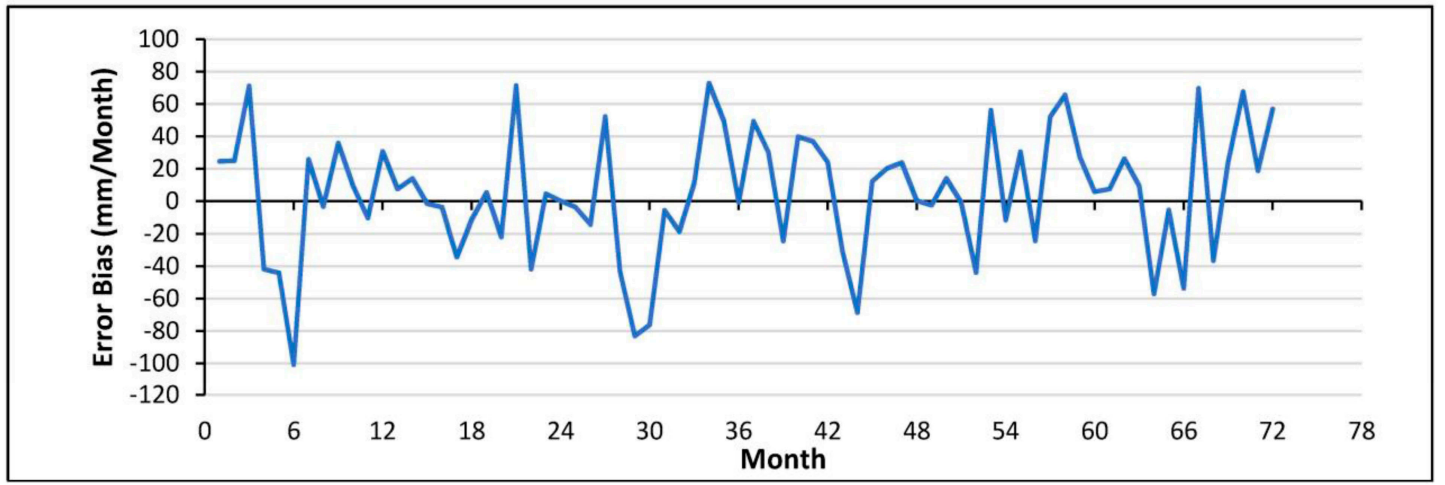

(b)

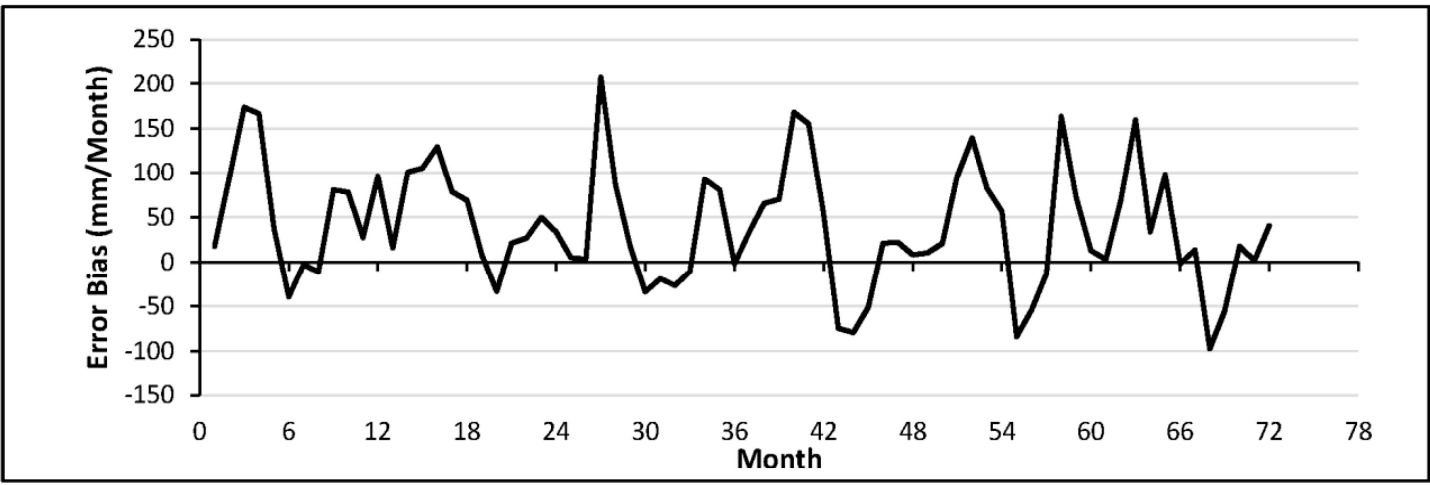

(c)

Figure 9. Monthly averaged bias of SRFEs for the 7 rain-gauge stations: (a) TMPA 3B42; (b) TMPA 3B42-RT and (c) CMORPH, 2003-2008.

The overall average monthly rainfall is well represented by the TMPA 3B42 as seen in Figure 10a. This is closely followed by the TMPA 3B42-RT (Figure 10b), but the CMORPH completely 
overestimates the monthly average rainfall except in the months of July and August where an underestimation is seen Figure 10c.

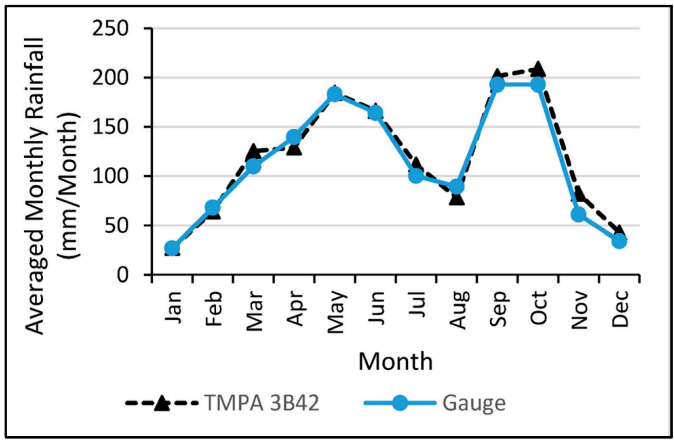

(a)

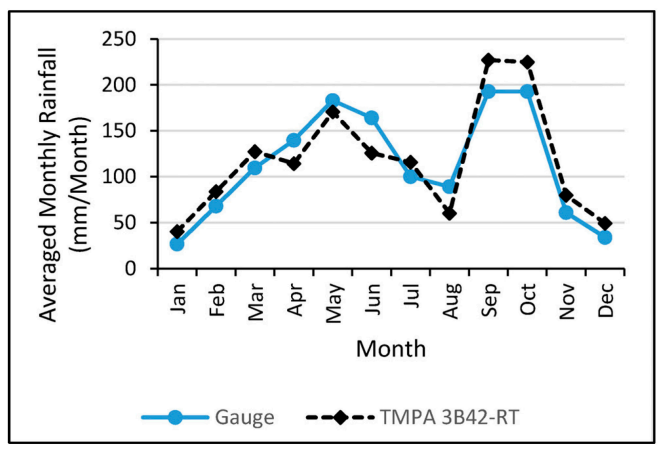

(b)

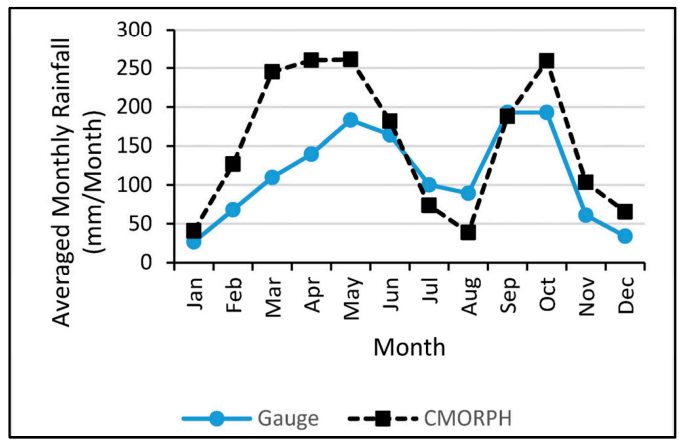

(c)

Figure 10. Averaged monthly rainfall (mm) obtained from SRFEs and rain gauges: (a) TMPA 3B42;

(b) TMPA 3B42-RT and (c) CMORPH, 2003-2008.

\subsection{Annual Rainfall Analysis}

The average annual rainfall and bias ratio for each year was computed to see how the annual rainfall estimated by the SRFEs compares with the gauge data. Table 3 shows the results of these computations.

Table 3. Comparison of SRFE and RG performances in the estimation of annual rainfall, 2003-2008.

\begin{tabular}{cccccccc}
\hline Year & $\begin{array}{c}\text { Gauge } \\
(\mathrm{mm})\end{array}$ & $\begin{array}{c}\text { 3B42 } \\
(\mathrm{mm})\end{array}$ & $\begin{array}{c}\text { Bias Ratio } \\
(\%)\end{array}$ & $\begin{array}{c}\text { CMORPH } \\
(\mathrm{mm})\end{array}$ & $\begin{array}{c}\text { Bias Ratio } \\
(\%)\end{array}$ & $\begin{array}{c}\text { 3B42-RT } \\
(\mathrm{mm})\end{array}$ & $\begin{array}{c}\text { Bias Ratio } \\
(\%)\end{array}$ \\
\hline 2003 & 1203.31 & 1353.38 & 12.47 & 1921.16 & 59.66 & 1224.76 & 1.78 \\
2004 & 1375.63 & 1481.27 & 7.68 & 1980.34 & 64.57 & 1363.37 & 13.30 \\
2005 & 1229.29 & 1272.26 & 3.50 & 1636.45 & 35.99 & 1178.86 & -2.03 \\
2006 & 1393.01 & 1333.83 & -4.25 & 1784.73 & 48.32 & 1505.53 & 25.12 \\
2007 & 1506.21 & 1504.68 & -0.10 & 2008.33 & 66.90 & 1673.98 & 39.11 \\
2008 & 1445.36 & 1579.17 & 9.26 & 1727.46 & 43.56 & 1572.29 & 30.66 \\
\hline
\end{tabular}

The TMPA 3B24 mostly overestimated the annual rainfall. It had a maximum overestimation of $12.47 \%$ and a minimum of $3.5 \%$. It has a mean of $8.23 \%$ overestimation. On the underestimation side, it showed a maximum of $4.25 \%$ in the year 2006 and a minimum of $0.1 \%$ in 2007. The TMPA 3B42 has a more likelihood of overestimating the annual rainfall. The TMPA 3B42-RT also showed a similar trend, maximum of $30.66 \%$ overestimation and a minimum of $1.78 \%$. It has a mean of $22 \%$ 
overestimation. It showed an underestimation only in the year 2005 with a value of $2.03 \%$. CMORPH hugely overestimates the annual rainfall with no underestimation. It showed a maximum of $66.9 \%$ and a minimum of $35.99 \%$ with a mean of $53.10 \%$.

\subsection{Seasonal Rainfall Analysis}

The basin falls within the southern sector of Ghana which have two wet seasons: the major season from March to July, and a minor season from September to November. A total of 24 out of 72 months analyzed for each station were in the dry season whereas the remaining 48 were in the wet season. All the satellite based products were able to depict the bimodal rainfall pattern within the basin as shown in Figure 11, although CMOPRH was seen to hugely overestimate the rainfall in the major wet season.

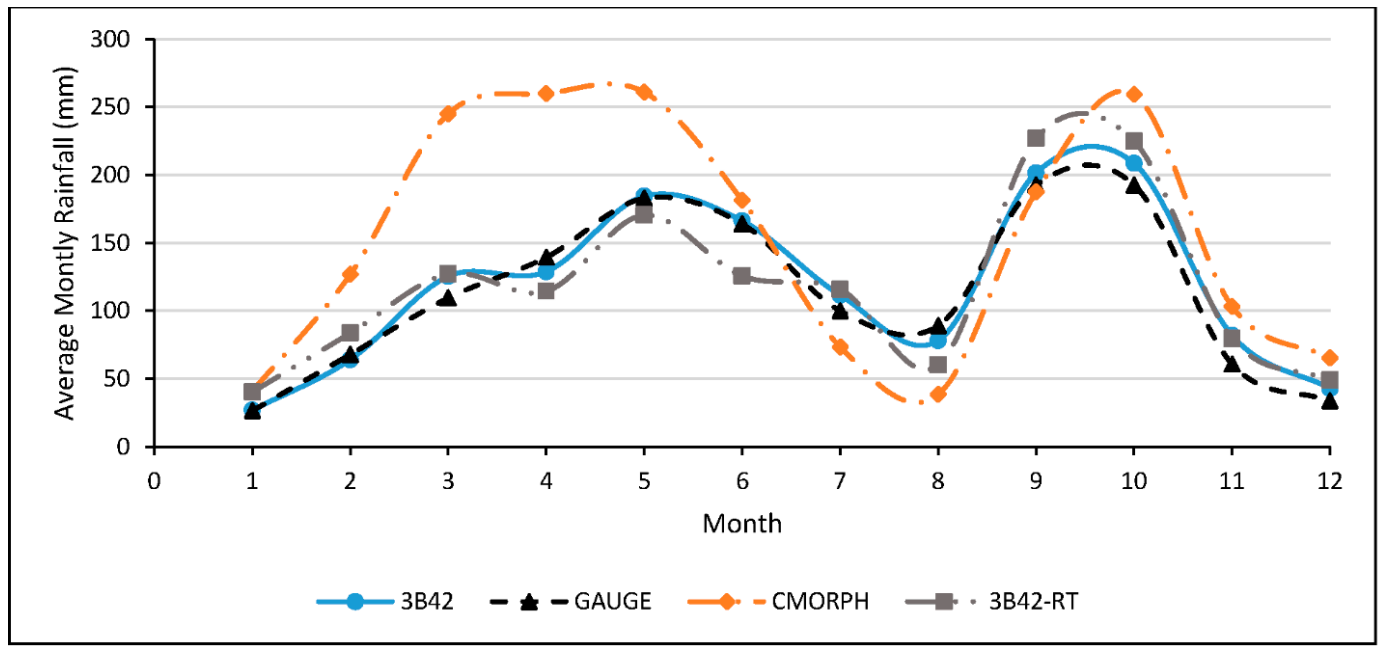

Figure 11. Annual variation of mean monthly rainfall of SRFEs and Gauge data, 2003-2008.

With the assumption that overestimation or underestimation within $0-10 \mathrm{~mm}$ bias is acceptable, computation of the number of months of bias falling within different bias ranges was computed. Percentage of months falling within the acceptable $\pm 10 \mathrm{~mm}$ was plotted for each season and for each station as shown in Figure 12. All the SRFEs were seen to perform better in the dry season (4-54\%) relative to the wet seasons $(2-27 \%)$. The overall performance of the SRFEs for the whole catchment as shown in Figure 13 shows that all the SRFEs are seasonally biased. They relatively perform better in the dry season compared to the rainy season.

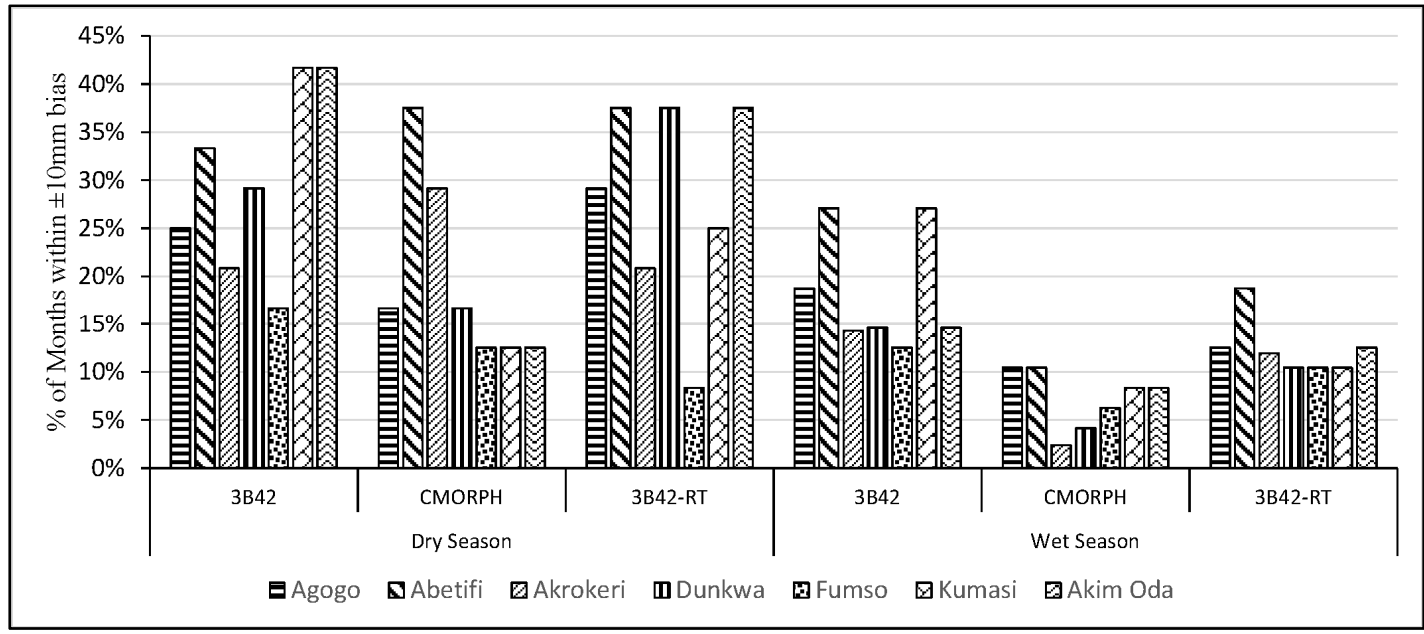

Figure 12. Comparison of performance of SRFEs for different seasons and stations, 2003-2008. 


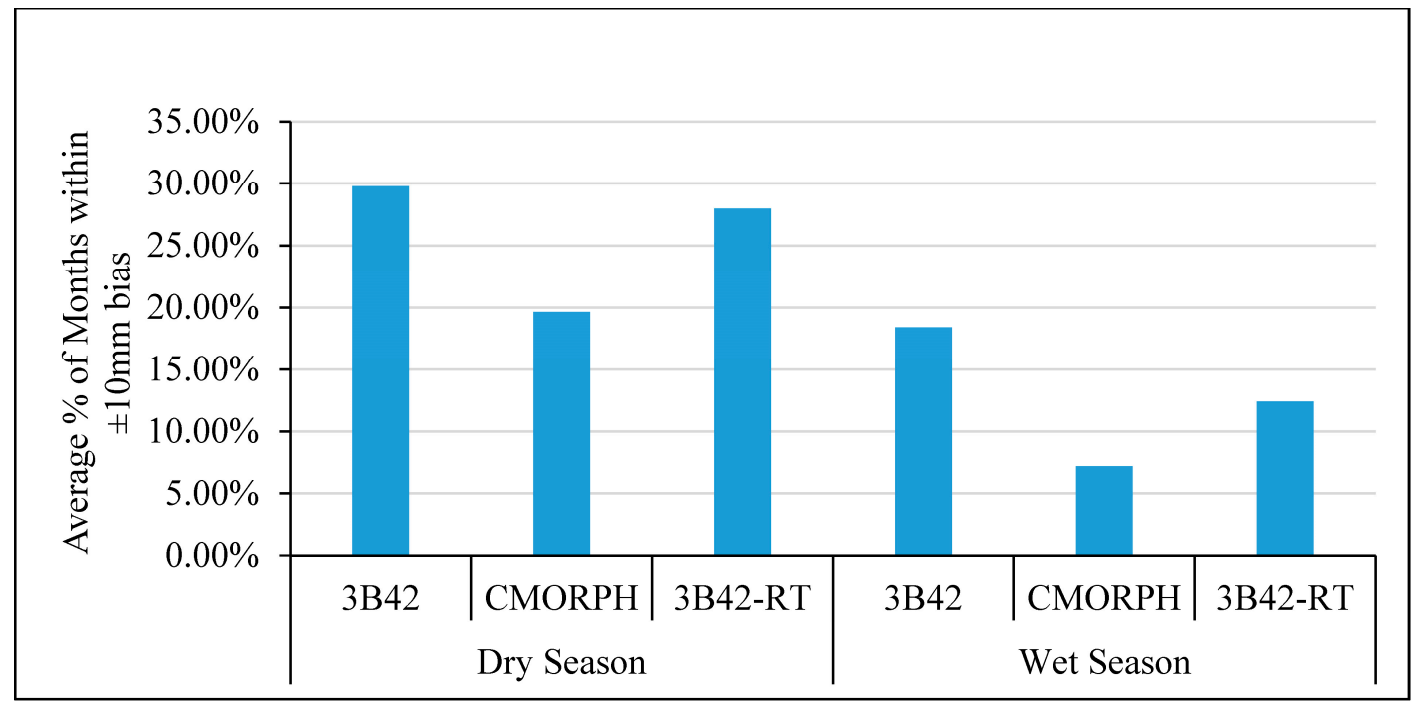

Figure 13. Overall performance of SRFEs for different seasons, 2003-2008.

\section{Conclusions}

Comparison of satellite products with gauge data showed that all the satellite products performed poorly on a daily time scale. On a monthly timescale, the computed correlation coefficient ranges between 0.5-0.91. This shows a moderate to strong positive linear relationship between satellite products and gauge data. Despite the positive correlation, the CMORPH mostly overestimated the rainfall on all time scales. Seasonal analysis of the products also showed the bias in the estimation. All the products performed well in the dry season compared to the wet season. On the overall, the TMPA 3B42 was seen to be the best product closely followed by the TMPA 3B42-RT. The CMORPH is not recommended for use in the basin. The good performance of the TMPA 3B42 can be attributed to the adjustment of the estimates using monthly rain gauge data. The poor performance of the CMORPH can be attributed to the fact that its estimates are based entirely on infrared sensors as compared to the TMPA products which are estimate from a combination of both infrared and microwave sensors. The microwave sensors have more direct and physical inference of rainfall. Overall, the TMPA products can be used in other ungauged basins with similar characteristics as the Pra basin.

Acknowledgments: The Civil Engineering Department, Kwame Nkrumah University of Science \& Technology provided the financial and enabling environment for this research work with support from government of Ghana research grant for graduate students. We also appreciate the support of the Ghana Meteorological Agency for providing historical rainfall data for the study.

Author Contributions: Collins Owusu conducted this research as part of his Masters thesis. The research idea was conceived by Kwaku A. Adjei and S. N. Odai. Kwaku A. Adjei was the supervisor and S. N. Odai as the mentor. Data Collection, preparation and analysis was carried out by Collins Owusu. Preparation of draft manuscript was done by Collins Owusu with Kwaku A. Adjei and S. N. Odai providing manuscript review and comments. All authors were involved in the final manuscript preparation and agreed to the publication of the contents of this paper.

Conflicts of Interest: The authors declare no conflict of interest.

\section{References}

1. Adjei, K. A.; Ren, L.; Appiah-Adjei, E. K. Validation of TRMM Data in the Black Volta Basin of Ghana. J. Hydrol. Eng. 2012, 17, 647-654.

2. Dinku, T.; Ceccato, P.; Grover-Kopec, E.; Lemma, M.; Connor, S. J.; Ropelewski, C. F. Validation of satellite rainfall products over East Africa's complex topography. Int. J. Remote Sens. 2007, 28, 1503-1526. 
3. Jameson, A. R.; Kostinski, A. B. Spurious power-law relations among rainfall and radar parameters. $Q J R$ Meteorol Soc 2002, 2045-2058.

4. Grimes, D. I. F.; Diop, M. Satellite-based rainfall estimation for river flow forecasting in Africa . I : Rainfall estimates and hydrological forecasts. 2004, 48, 567-584.

5. Kidd, C.; Bauer, P.; Turk, J.; Huffman, G. J.; Joyce, R.; Hsu, K. L.; Braithwaite, D. Intercomparison of highresolution precipitation products over northwest Europe. J. Hydrometeorol. 2012, 67-83.

6. Qin, Y.; Chen, Z.; Shen, Y.; Zhang, S.; Shi, R. Evaluation of Satellite Rainfall Estimates over the Chinese Mainland. J. Remote Sens. 2014, 11649-11672.

7. Bitew, M. M.; Gebremichael, M. Assessment of satellite rainfall products for streamflow simulation in medium watersheds of the Ethiopian highlands. Hydrol. Earth Syst. Sci. 2011, 15, 1147-1155.

8. Huffman, G. J.; Bolvin, D. T.; Nelkin, E. J.; Wolff, D. B.; Adler, R. F.; Gu, G.; Hong, Y.; Bowman, K. P.; Stocker, E. F. The TRMM Multisatellite Precipitation Analysis (TMPA): Quasi-Global, Multiyear, Combined-Sensor Precipitation Estimates at Fine Scales. J. Hydrometeorol. 2007, 8, 38-55.

9. Joyce, R. J.; Janowiak, J. E.; Arkin, P. A.; Xie, P. CMORPH: A Method that Produces Global Precipitation Estimates from Passive Microwave and Infrared Data at High Spatial and Temporal Resolution. J. Hydrometeorol. 2004, 5, 487-503.

10. WRC Pra Basin IWRM Plan; Water Resource Commission, Ghana, 2012.

11. Owusu, K.; Waylen, R. P. The Changing Rainy Season Climatology of Mid-Ghana. Theor. Appl. Climatol. 2013, $112,419-430$.

12. Nkrumah, F.; Ama, N.; Klutse, B.; Adukpo, D. C.; Owusu, K.; Quagraine, K. A.; Owusu, A.; Jr, W. G. Rainfall Variability over Ghana : Model versus Rain Gauge Observation. Int. J. Geosci. 2014, 5, 673-683.

13. Akrasi, S. A.; Ansa-Asare, O. D. Assessing Sediment and Nutrient Transport in the Pra Basin of Ghana. West Afr. J. Appl. Ecol. 2008, 13, 45-54.

14. Thiemig, V.; Rojas, R.; Zambrano-Bigiarini, M.; Levizzani, V.; ROO, A. D. Validation of Satellite-Based Precipitation Products over Sparsely Gauged African River Basins. J. Hydrometeorol. 2012, 13, 1760-1783.

15. Yapo, P. O.; Gupta, H. V.; Sorooshian, S. Automatic calibration of conceptual rainfall-runoff models: sensitivity to calibration data. J. Hydrol. 1996, 181, 23-48.

16. Romilly, T. G.; Gebremichael, M. Evaluation of satellite rainfall estimates over Ethiopian river basins. Hydrol Earth Syst Sci 2011, 15, 1505-1514.

(C) 2016 by the authors; licensee Preprints, Basel, Switzerland. This article is an open access article distributed under the terms and conditions of the Creative Commons by Attribution (CC-BY) license (http://creativecommons.org/licenses/by/4.0/). 